\title{
Putting the Disability Discrimination Act into perspective
}

Received: 6 August 2003

\section{Steve Goss}

is DDA Programme Manager for Boots Retail. He was sponsored through university by Boots in 1988 and became a chartered engineer in 1997. He has held several key operational positions within the company, and since 2000 has been heavily involved in leading business change programme initiatives. He has been responsible for the implementation of the Boots DDA compliance programme for the last year and has spoken extensively on the subject.

\section{Abstract}

Despite the fact that the Disability Discrimination Act (DDA) is dated 1995, there is a general perception in the property world that it does not come into force until 1 October 2004. This is not correct. While from that date service providers may have to make 'reasonable adjustments' to retail premises, many parts of the Act are already in force.

A second major misconception also exists. It is believed that compliance with the Act is purely about the provision of automatic entrance doors and permanent ramps to premises. In actual fact, the Act encompasses much more and impacts upon a much wider and deeper part of any retailer's in-store and outof-store service provision.

This paper is intended to familiarise the reader with the key requirements of Part III of the Act, to identify the significant issues and duties for the retail property industry and to define how this forms an integral and vital part of any large retailer's overall, sustainable, DDA compliance solution.

\section{Keywords:}

disability, reasonable adjustments, Part III, discrimination, responsibility, property portfolios, change management, programme management

Steve Goss

Boots Retail

Operations Improvement

Head Office

D9o East Fo6

Nottingham

NG90 1BS, UK

Tel: +44 (o)1159495460

E-mail: steve.goss@boots-plc.com

\section{INTRODUCTION}

The Disability Discrimination Act $1995^{1}$ was passed through UK Parliament in that year and is governed by the Department of Work and Pensions. The Act's high-level target is to introduce measures aimed at ending the discrimination which people with disabilities can face. The Act itself is split into eight parts:

- Part I: Disability

- Part II: Employment

- Part III: Discrimination in other areas 
DDA Part III

\section{Part III duties}


It must be highlighted that it is only physical features which need a DDA-compliant solution by 1 October 2004. All other areas of a company's service provision should already be compliant, as 'reasonable adjustments' should have been completed by 1 October 1999. The way that retail staff treat customers with disabilities, for instance, should already be compliant, so that those customers are not treated less favourably.

\section{Example: A retail premises has a set of steps to its main entrance}

- In terms of removing the feature, this could entail the provision of a permanent ramp.

- In terms of altering the feature, this could involve the provision of a temporary ramp (put in place by retail staff upon request from disabled customers via an intercom system).

- A reasonable means of avoiding the physical feature could be by the use of an alternative entrance point (potentially even a staff entrance if customers are escorted).

- Provision of that service by alternative means could entail the use of an internet shopping service.

\section{Unlawful acts of discrimination}

With respect to 'committing an unlawful act of discrimination', it is unlawful for a service provider to:

- discriminate against a disabled person (ss. 19 and 20):

- by refusing to provide (or deliberately not providing) any service which it provides (or is prepared to provide) to members of the public; or

- in the standard of service which it provides to the disabled person or the manner in which it provides it; or

- in the terms on which it provides a service to the disabled person

- and it cannot show that the treatment in question is justified

- discriminate against a disabled person (s. 21):

- in failing to comply with any duty imposed on it by s. 21 (a duty to make reasonable adjustments) in circumstances in which the effect of that failure is to make it impossible or unreasonably difficult for the disabled person to make use of any such service

- and it cannot show that the failure to comply with that duty is justified.

Guidance

In an attempt to offer guidance, the Disability Rights Commission has issued Approved Codes of Practice (ACOPs), ${ }^{2}$ the latest version of which was issued in July 2002. These codes offer a more readable and easily understood interpretation of the Act, with reference to specific examples to highlight key points.

It must, however, be borne in mind that while the ACOPs do 
offer guidance, a definitive specification as to what is deemed to be compliant and what is not still does not exist. It is only case law after 1 October 2004 that will provide such detail, and it will take a considerable time after that for a suitably defined set of case law precedents to be established. This in itself then creates two major problems for the service provider.

First, there are no guarantees that the solution they are instigating will be fully compliant, and as a result they have to rely on information from other sources. This has led to an increasing reliance and focus on retail forums to establish peer positioning. With a few exceptions, most retailers now seem to be trying to ensure that they are 'among the pack' rather than exposing themselves as exemplary or below average. Happily, the DDA Helpline $^{3}$ has been established to offer direct access to experts in the Act and its application.

Secondly, there is a misplaced expectation among the disabled community that all retail premises will reach a level of 'perfect' compliance by 1 October 2004. This expectation has been created as a direct result of the detail to which accredited access consultants ${ }^{4}$ audit retail premises. This level of detail is quite correct, but still leaves the retailer free to define their own interpretation of 'reasonable adjustment'. As an example, an audit would define the compliance of all the entrance points to a retail premises, but the retailer may decide to make only one entrance point compliant. The retailer is providing a compliant solution, but the disabled customer may expect more. Given today's tough retail environment, with very few cash-rich retailers, this is increasingly more likely to occur. There is an increased focus on driving the retail business in a value-maximising way, and as a result retailers may decide to opt for an average/minimal level of compliance rather than an exemplary level, to leave cash free to expand or consolidate their business. It could be suggested that this expectation needs to be jointly managed by the Department of Work and Pensions and the Disability Rights Commission well in advance of 1 October 2004.

\section{THE IMPACT ON THE RETAIL PROPERTY INDUSTRY}

The key to defining the impact on the retail property industry of the Act is in the definition of accountabilities and responsibilities. Such definitions must be included within landlord/tenant agreements and contracts to protect both parties. For those retailers with a sizeable property portfolio, this can be a lengthy and costly exercise.

\section{Responsibility}

The DDA compliance of the sales-floor area of a retail property is clearly the responsibility of the service provider (generally the tenant). The allocation of DDA responsibility, and the extent of that responsibility, for any 'back-shop' or 'common' areas depends upon how those areas are used. A process for allocating responsibility is summarised in Figure 2. 

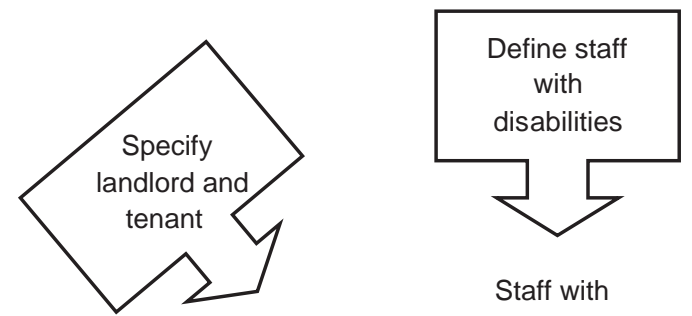

Staff with disabilities use

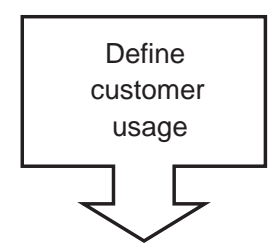

Customers use

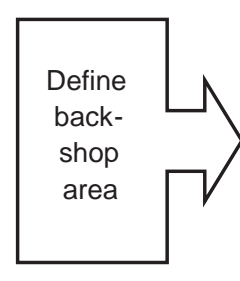

Back-shop area

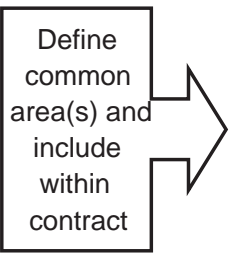

Common area(s)

\begin{tabular}{|c|c|}
\hline $\begin{array}{c}\text { Service } \\
\text { provider has } \\
\text { responsibility } \\
\text { for solution to } \\
\text { staff disability } \\
\text { (Part II) }\end{array}$ & $\begin{array}{c}\text { Service } \\
\text { provider has } \\
\text { responsibility } \\
\text { for solution to } \\
\text { all disabilities } \\
\text { (Part III) }\end{array}$ \\
\hline $\begin{array}{l}\text { Landlord has } \\
\text { responsibility } \\
\text { for solution to } \\
\text { staff disability } \\
\text { (Part II) }\end{array}$ & $\begin{array}{c}\text { Service } \\
\text { provider has } \\
\text { responsibility } \\
\text { for solution to } \\
\text { all disabilities } \\
\text { (Part III) }\end{array}$ \\
\hline
\end{tabular}

Figure 2: Back-shop and common area DDA responsibility allocation matrix

\section{The effect on property portfolios}

It can be seen that the inputs required before a decision can be made are extensive, and are further complicated by the fact that all permutations of usage and area are possible. Add to this the influence of other legislation, such as health and safety, and the whole task of defining responsibilities, accountabilities and a compliance solution becomes more demanding. The situation will inevitably arise where there is conflict between different legislation, and a decision has to be made as to which is 'dominant'. Invariably the well-being of staff and customers comes first, but this then necessitates the need to secure, justify and record such a decision.

The DDA is likely to have little effect on property values, but is more likely to impact upon property portfolios. There may well be a push to dispose of unwanted and potentially non-compliant properties by landlords and property management organisations in advance of 1 October 2004 to avoid issues of 'duty' under the Act. Potential property purchasers will need to be aware of this, and could demand that a property is not considered for purchase before a fully accredited DDA compliance audit has been undertaken and all remedial works have been identified and costed.

It is expected that the Act will affect rent review valuation with respect to 'works carried out as an obligation' and reinstatement at the end of the lease. The whole process of gaining landlord consent for DDA compliance modification works will consume additional resources and finance, and will be further complicated by variances 
in local authority standards and approaches to the requirements of the Act - differences in the way local authorities have dealt with the requirement for fire refuges for disabled people being one example.

The importance of a clearly defined process to manage successfully all of the issues discussed so far cannot be stressed highly enough, and it is how this can be achieved that is detailed in the following section.

\section{MANAGING THE IMPACT OF THE ACT ON A COMPANY'S SERVICE PROVISION}

The impact that the DDA has on the service provision of a retailer is extensive in terms of its breadth and depth. As a result, there are four main prerequisites that a typical large retailer should meet before the consolidated management approach necessary to meet the requirements of the Act can be progressed.

First, a dedicated resource should be allocated. This has several benefits. It ensures that the delivery of the required programme of events is given full attention and that key resources are not diverted by other company initiatives or by activities deemed to be part of the 'day job'. It also creates a discreet point of reference within the organisation to which any related or unforeseen issues can be directed and where they can be handled. With respect to a company approach to DDA compliance, it also supports/underpins a higher level of commitment to corporate and social responsibilities.

Secondly, it should be recognised that the breadth of the impact defines the need to manage the Act in terms of a programme and not merely a project - a 'programme' being defined as a series of many interlinked and therefore interdependent projects. The depth of the impact dictates that it is not sufficient merely to make things happen now. Solutions should be sustainable well into the future and incorporated into working practices and firmly embedded within the company culture. As a result, the impact depth defines the need to employ a change management approach. To pull the two dimensions together, the breadth and depth of the potential impact therefore define a change and programme management scenario.

Thirdly, there should be a firm understanding that effective stakeholder management at all levels of the business, coupled with the securing of executive sponsorship, underpins the whole change programme. It is a rare luxury to be able to form a large dedicated team with a membership representing all areas of the business. It is more likely that a 'virtual team' is guided and coached through a change programme by a programme manager, drawing upon extensive stakeholder management skills, experiences and methodologies.

Finally, there should be the solid comprehension that the implementation of a successful compliance plan is based around the company's service provision. This service provision should be 


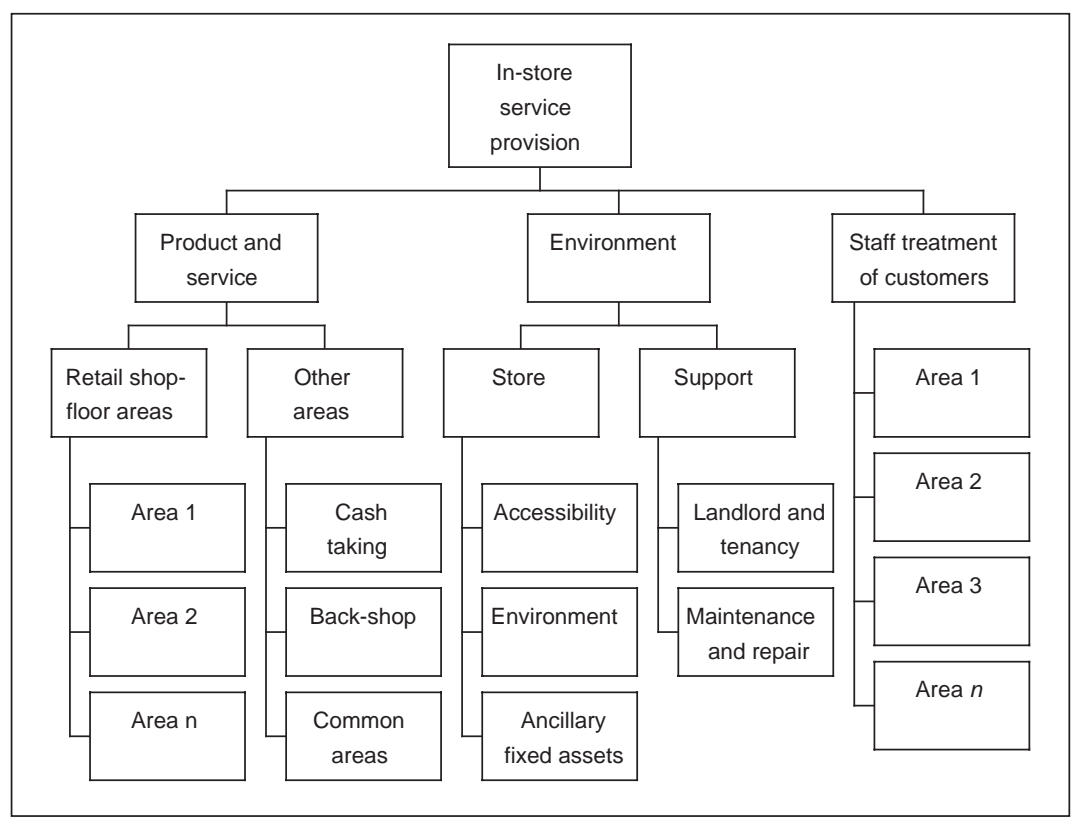

Figure 3: In-store service provision impacted upon by the Act

defined for all areas of the business that are impacted upon by the Act. It invariably defines the retail customer journey and not the structure of the company. After all, it is at the point of service provision that compliance with the DDA is ultimately judged.

Once these prerequisites have been met it is then possible, for each service provision area, to:

- define non-compliance

- define compliance solutions

— implement compliance solutions

- incorporate those solutions into working practices.

\section{Compliance management systems}

The company's service provision areas likely to be affected by the Act depend upon the company size, and the nature of the business and market that the retailer operates in. As a general guide, this effect can be split between those services being delivered 'in store' and those being delivered 'out of store'. The in-store impact is defined in Figure 3, and the out-of-store impact in Figure 4.

The consolidation of the whole management approach to producing a sustainable, company-wide compliance solution is achieved via the creation of a compliance management system. The primary functions of such a system are to enable the owner to prove/defend its compliance position and to facilitate the management of compliance initiatives into the future. The system should be fully accessible to all those with DDA accountabilities and responsibilities within the organisation, especially those within the retail premises, so that they can manage their own store-specific compliance plan. 


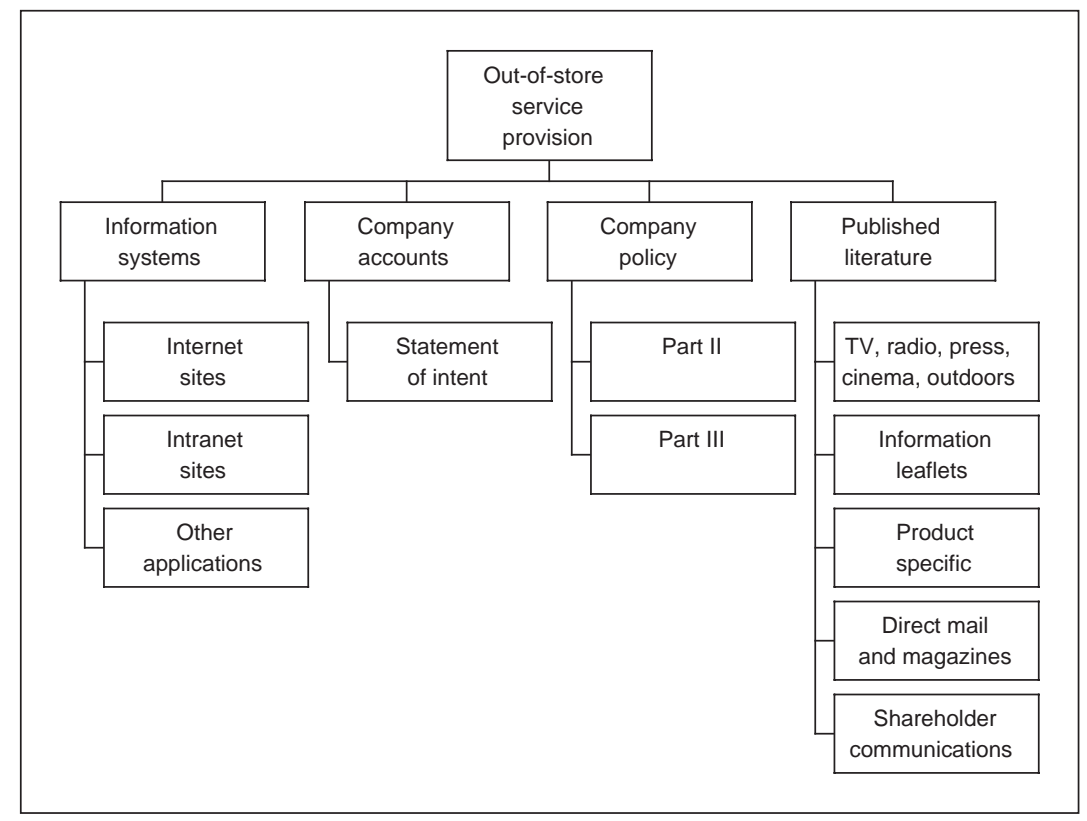

Figure 4: Out-of-store service provision impacted upon by the Act

\section{CONCLUSION}

The issues raised in this paper are just a few of the many that need to be addressed by the retail property industry and by retailers in general when responding to the requirements of the DDA. Those requirements are still, as yet, not definitively defined, and will remain so, in the absence of specific case law, for some considerable time to come. In the meantime, a consolidated and managed approach to compliance is recommended. Responsibilities and accountabilities for all stages, from the definition of non-compliance to the incorporation of compliance solutions into working practices, must be defined and established to ensure success.

In summary, the aim of the Act is to 'introduce measures aimed at ending the discrimination which people with disabilities can face'. If this is to be achieved, it can only be realised through working partnerships between service providers and service receivers. The basis for this is a general understanding between both parties that 'reasonable' works both ways and that they must work together to achieve an amicable level of compliance.

\section{References}

1. The Disability Discrimination Act 1995 (1995) Chapter 50.

2. The Disability Discrimination Act 1995 - Code of Practice - Rights of Access Goods, Facilities, Services and Premises (commencement date 27 May 2002).

3. DDA Helpline: tel: 08457 622633; faxback service: 08457 622611; textphone: 08457 622644 .

4. National Register of Access Consultants (NRAC), www.nrac.org.uk.

\section{(C) Boots Group PLC}

